\title{
Genetic mixed-stock analysis of Atlantic herring populations in a mixed feeding area
}

\author{
Dorte Bekkevold $^{1, *}$, Lotte A. W. Clausen ${ }^{1}$, Stefano Mariani ${ }^{2,9}{ }_{\text {, Carl André }}{ }_{\text {, }}$ \\ Emma M. C. Hatfield ${ }^{4}$, Else Torstensen ${ }^{5}$, Nils Ryman ${ }^{6}$, Gary R. Carvalho ${ }^{7}$, \\ Daniel E. Ruzzante ${ }^{8}$ \\ ${ }^{1}$ National Institute of Aquatic Resources, Technical University of Denmark, Vejlsøvej 39, 8600 Silkeborg, Denmark \\ ${ }^{2}$ Department of Biological Sciences, University of Hull, Hull HU6 7RX, UK \\ ${ }^{3}$ Department of Marine Ecology-Tjärnö, University of Gothenburg, 45296 Strömstad, Sweden \\ ${ }^{4}$ Marine Scotland Science, Marine Laboratory, Aberdeen AB11 9DB, UK \\ ${ }^{5}$ Institute of Marine Research, Research Station Flødevigen, 4817 His, Norway \\ ${ }^{6}$ Department of Zoology, Stockholm University, 10691 Stockholm, Sweden \\ ${ }^{7}$ Molecular Ecology and Fisheries Genetics Laboratory, School of Biological Sciences, University of Wales, Bangor \\ LL57 2UW UK \\ ${ }^{8}$ Department of Biology, Dalhousie University, Halifax NS B3H 4J1, Canada \\ ${ }^{9}$ Present address: School of Biology \& Environmental Science, University College Dublin, Belfield, Dublin 4, Ireland
}

\begin{abstract}
Determining spatio-temporal distributions of fish populations is of interest to marine ecology, in general, and to fisheries science in particular. Genetic mixed-stock analysis is routinely applied in several anadromous fishes for determining migratory routes and timing but has rarely been used for marine fishes, for which population differentiation is commonly weak and the method presumably less powerful. We used microsatellite information for Northeast Atlantic herring Clupea harengus L. populations and mixed stocks to address 2 questions. We used simulated mixture samples and 3 different statistical approaches to determine whether mixed stock composition could be determined with accuracy. Simulations showed that the applied approaches and mixture samples of 100 individuals enabled detailed composition analyses on a regional level, with resolution for tracing the ecologically dominant Rügen (Greifswalder Bodden) herring population. We then estimated spatio-temporal variation in herring migratory behaviour in the Skagerrak from 17 mixed samples collected over 2 seasons and $2 \mathrm{yr}$, and identified hitherto undescribed differences in distributions among populations that feed and winter in the area.
\end{abstract}

KEY WORDS: Genetic clustering · Genetic stock identification · GSI - Population structure · Simulation analysis $\cdot$ Skagerrak $\cdot$ Baltic Sea $\cdot$ Migration $\cdot$ Clupea harengus

\section{INTRODUCTION}

Understanding the dynamics of marine fishes requires knowledge about population level processes, and recent modeling studies demonstrate the importance of taking population specific exploitation rates into consideration in fisheries science and management (Kell et al. 2009, Kerr et al. 2010). However, inference about spatial distributions and exploitation of individual populations is greatly complicated when stocks are made up of fish from mixed population origin and are exploited disproportionately over time and space. Such heterogeneity is especially pertinent to population demography and management where respective populations differ in biological characteristics and/or abundance. Genetic mixed- 
stock analysis (MSA) comprises a number of statistical methods developed to estimate the composition of samples of individuals of mixed origin. MSA has been applied widely in anadromous salmonids (e.g. Ruzzante et al. 2004, Beacham et al. 2005, Koljonen et al. 2005, Smith et al. 2005, Gauthier-Ouellet et al. 2009, Miller et al. 2010), but in spite of the method's large potential for determining spatially and temporally explicit migratory behaviour, relatively few studies have yet been conducted in marine fishes (Waples \& Naish 2009). One of the reasons for this paucity is that the generally modest levels of differentiation among marine populations (e.g. Ward et al. 1994) limit the statistical resolution for genetic stock identification (GSI), and, therefore, MSA (Manel et al. 2005, Waples \& Gaggiotti 2006). However, when detailed sampling of the main populations contributing to mixed aggregations is attainable, approaches can be designed to overcome problems with low genetic resolution among populations (see e.g. Ruzzante et al. 2000, 2006).

Atlantic herring Clupea harengus L. is an abundant and widely distributed marine pelagic fish that spawns on substrate in coastal areas throughout most of the north Atlantic (Iles \& Sinclair 1982). Most herring populations are migratory and often congregate on common feeding and wintering grounds where aggregations may consist of mixtures of individuals from several populations. One such area is found in the Skagerrak and eastern North Sea (ICES division IVaE). Here, mixed feeding aggregations generally comprise herring from the North Sea and the area spanning the transition zone between the North Sea and the Baltic Sea proper (here collectively referred to as the 'western Baltic Sea'). North Sea herring in the Skagerrak mainly constitute juveniles from populations spawning along the east coast of Britian and in the English Channel that drift as larvae into the Skagerrak, where they feed during their first 1 to $2 \mathrm{yr}$ (Corten 1986, Johannessen \& Moksness 1991). Western Baltic Sea herring in the Skagerrak comprise a presumably more diverse group of local populations. Main components represent: (1) adult herring that spawn in spring around the island of Rügen in the western Baltic and migrate annually to the Skagerrak to feed (Biester 1979, Aro 1989), (2) relatively small populations spawning in the Kattegat and inner Danish waters, and (3) local populations from the Skagerrak (Rosenberg \& Palmén 1982). The Rügen herring are assumed to make up the majority of the western Baltic Sea herring in the area (ICES 2010). Although all population components are present in the Skagerrak during different times of the year, their spatial distributions and relative contributions to the mixed feeding and wintering aggregations remain unresolved (ICES 2010). Atlantic herring in the area thus comprise a good model system for examination of a relatively complex MSA scenario in an abundant marine fish.

Herring migratory patterns and habitat use in the Skagerrak have previously been studied based on population differences in morphological traits such as vertebral number, spawning time (spring, autumn or winter; estimated from otolith microstructure) and age distributions (review in ICES 2010). However, the statistical basis for assigning individuals to populations based on environmentally influenced traits that may exhibit large temporal variation remains uncertain (Bierman et al. 2010). Seminal microsatellite DNA studies demonstrate weak but significant genetic differentiation among populations within the Baltic Sea (Jørgensen et al. 2005a), among components in the transition zone between the North Sea and the Baltic Sea (Bekkevold et al. 2005), and among North Sea populations (Mariani et al. 2005). Ruzzante et al. (2006) used MSA with genetic baseline information obtained from those studies to estimate the proportions of herring originating from the North Sea, Skagerrak and western Baltic in samples from feeding grounds in the North Sea and Skagerrak. They pooled information for samples of feeding and wintering herring collected across the Skagerrak to show that otoliths-based estimates of hatching time generally correspond with the genetic origin of spring vs. autumn and winter spawning populations. The study also corroborated the prediction that juveniles feeding in the Skagerrak originate mainly from autumn and winter spawning populations in the North Sea and English Channel, whereas most herring older than $2 \mathrm{yr}$ originate from spring spawning populations in the Skagerrak and western Baltic. However, resolving spatio-temporal aspects of contributions, e.g. with respect to which populations migrate within the Skagerrak have not previously been attempted. Here, we use genetic baseline information from the studies by Bekkevold et al. (2005) and Mariani et al. (2005) in a MSA. This analysis is targeted to determine spatial relationships of herring from the North Sea, Skagerrak, inner Danish waters, and Rügen in mixed fishery samples collected across SW-NE transects in the Skagerrak in both summer and winter, and repeated over 2 yr. Moreover, we use simulated mixed-stocks to assess the accuracy of the estimated stock compositions. Using a related MSA approach, Ruzzante et al. (2006) reported composition estimates for these mixture samples pooled 
across all sampling locations using a different baseline designed to optimise that more general approach. Here, we also reanalyse their empirical data with the objective of estimating fine-scale spatial and temporal population differences in migratory behaviour and habitat use. We specifically seek to disentangle migratory patterns of the dominant Rügen population from those of populations from the Kattegat and inner Danish waters, which are assumed to be smaller and hence potentially more vulnerable to overexploitation.

\section{MATERIALS AND METHODS}

\section{Samples of herring}

Detailed information on the genetic composition of the baseline samples is reported in Bekkevold et al. (2005) and Mariani et al. (2005). Briefly, samples of spawning herring were obtained from 18

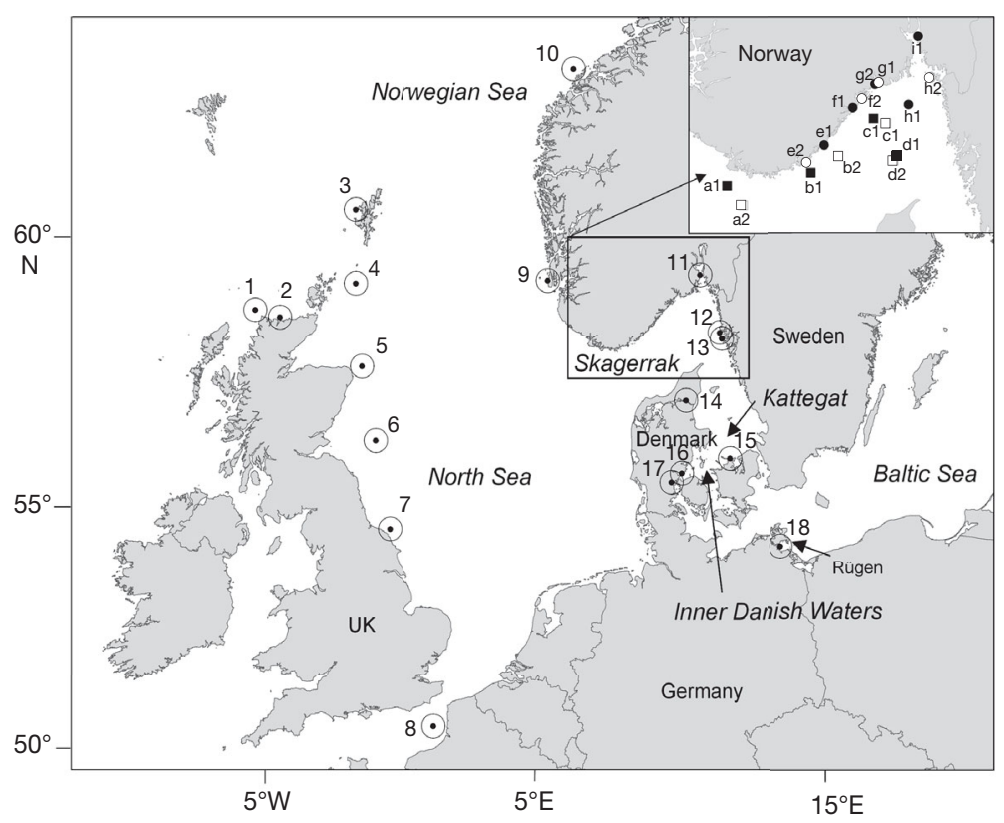

Fig. 1. Clupea harengus. Sampling locations for the genetic mixed-stock analysis baseline and mixed-stock collections (inset). Spawning location numbers refer to Table 1 and mixed-stock sample ID to Table 2. In inset, squares indicate summer samples, circles indicate winter samples and filled and open symbols indicate samples collected in 2002 and 2003, respectively

Table 1. Clupea harengus. Samples in genetic mixed-stock analysis baseline by reporting group. Locality numbers refer to Fig. 1. Details about samples are found in Mariani et al. (2005) for localities 1 to 8 and in Bekkevold et al. (2005) for localities 9 to 18. In simulations, the baseline was based solely on samples collected in 2003 and simulated mixed-stocks on samples collected in 2002, whereas the baseline used to analyse real mixed-stock samples comprised allele information for 2002 and 2003 samples combined within population (see 'Mixed-stock simulation analyses'). -: no data available

\begin{tabular}{|c|c|c|c|c|c|c|c|}
\hline $\begin{array}{l}\text { Reporting } \\
\text { group }\end{array}$ & $\begin{array}{l}\text { Sampling } \\
\text { locality }\end{array}$ & $\begin{array}{c}\text { Locality } \\
\text { no. }\end{array}$ & $\begin{array}{l}\text { Latitude/ } \\
\text { Longitude }\end{array}$ & $\begin{array}{l}\text { Sampling } \\
\text { month }\end{array}$ & $\begin{array}{c}\text { Sample } \\
\text { size } 2002\end{array}$ & $\begin{array}{c}\text { Sample } \\
\text { size } 2003\end{array}$ & $\begin{array}{l}\text { Spawning } \\
\text { time }\end{array}$ \\
\hline \multirow[t]{10}{*}{ North Sea } & Cape Wrath & 1 & $58^{\circ} 38^{\prime} \mathrm{N} / 5^{\circ} 13^{\prime} \mathrm{W}$ & August & 84 & 96 & Autumn \\
\hline & Whiten Head & 2 & $58^{\circ} 36^{\prime} \mathrm{N} / 4^{\circ} 20^{\prime} \mathrm{W}$ & September & 99 & 86 & Autumn \\
\hline & Shetland & 3 & $60^{\circ} 29^{\prime} \mathrm{N} / 1^{\circ} 40^{\prime} \mathrm{W}$ & August & 90 & - & Autumn \\
\hline & Orkney & 4 & $59^{\circ} 12^{\prime} \mathrm{N} / 1^{\circ} 40^{\prime} \mathrm{W}$ & August & 106 & 84 & Autumn \\
\hline & Aberdeen & 5 & $57^{\circ} 42^{\prime} \mathrm{N} / 1^{\circ} 27^{\prime} \mathrm{W}$ & August & - & 91 & Autumn \\
\hline & Berwick & 6 & $56^{\circ} 18^{\prime} \mathrm{N} / 0^{\circ} 58^{\prime} \mathrm{W}$ & August & 100 & - & Autumn \\
\hline & Flamborough & 7 & $54^{\circ} 34^{\prime} \mathrm{N} / 0^{\circ} 27^{\prime} \mathrm{W}$ & September & 97 & 77 & Autumn \\
\hline & Downs & 8 & $50^{\circ} 7^{\prime} \mathrm{N} / 0^{\circ} 25^{\prime} \mathrm{E}$ & November & 80 & 63 & Winter \\
\hline & Karmøy & 9 & $59^{\circ} 14^{\prime} \mathrm{N} / 05^{\circ} 10^{\prime} \mathrm{E}$ & March & 100 & - & Spring \\
\hline & Møre & 10 & $62^{\circ} 78^{\prime} \mathrm{N} / 06^{\circ} 08^{\prime} \mathrm{E}$ & February & - & 78 & Spring \\
\hline \multirow[t]{3}{*}{ Skagerrak } & Tjöme & 11 & $59^{\circ} 35^{\prime} \mathrm{N} / 10^{\circ} 55^{\prime} \mathrm{E}$ & March & 120 & 116 & Spring \\
\hline & Måseskär & 12 & $58^{\circ} 32^{\prime} \mathrm{N} / 11^{\circ} 32^{\prime} \mathrm{E}$ & March & 100 & 99 & Spring \\
\hline & Flatbrotten & 13 & $58^{\circ} 32^{\prime} \mathrm{N} / 11^{\circ} 25^{\prime} \mathrm{E}$ & March & 100 & 100 & Spring \\
\hline Kattegat and Inner & Limfjord & 14 & $57^{\circ} 06^{\prime} \mathrm{N} / 10^{\circ} 06^{\prime} \mathrm{E}$ & May & - & 99 & Spring \\
\hline \multirow{3}{*}{$\begin{array}{l}\text { Danish waters } \\
\text { (KIDW) }\end{array}$} & Kattegat & 15 & $55^{\circ} 73^{\prime} \mathrm{N} / 11^{\circ} 37^{\prime} \mathrm{E}$ & May & 44 & 99 & Spring \\
\hline & Kolding & 16 & $55^{\circ} 49^{\prime} \mathrm{N} / 09^{\circ} 54^{\prime} \mathrm{E}$ & April & 100 & 70 & Spring \\
\hline & Lillebælt & 17 & $55^{\circ} 45^{\prime} \mathrm{N} / 09^{\circ} 72^{\prime} \mathrm{E}$ & April & - & 100 & Spring \\
\hline \multirow[t]{3}{*}{ Rügen } & Rügen & 18 & $54^{\circ} 23^{\prime} \mathrm{N} / 13^{\circ} 43^{\prime} \mathrm{E}$ & March & 100 & - & Spring \\
\hline & & & & April & 98 & 100 & Spring \\
\hline & & & & May & 100 & 100 & Spring \\
\hline
\end{tabular}


locations widely distributed in the North Sea and adjacent areas. Baseline samples represent the majority of populations contributing migrants to the Skagerrak (Fig. 1). Of the 18 locations, 14 were re-sampled in 2 consecutive years to ascertain temporal stability of allele frequencies (Table 1). One location (Rügen) was sampled in March, April and May 2002 and in April and May 2003 to encompass potential effects of genetically differentiated spawning waves (Jørgensen et al. 2005b). Sagittal otolith growth patterns were used to estimate fish age (following procedures detailed in ICES 2003) and spawning season (spring, autumn or winter) following Clausen et al. (2007).

Data for mixed feeding aggregations were collected and analysed as described in Ruzzante et al. (2006). Briefly, herring were sampled by trawling along SW-NE transects in the Skagerrak during scientific surveys in summer and winter 2002 and 2003 (Fig. 1, Table 2). The age and hatching season were recorded for subsets of these fish following the same procedure as for spawning samples.

\section{Molecular data}

Baseline and mixed-stock individuals were genotyped for 9 tetra-nucleotide microsatellites as de- tailed in Bekkevold et al. (2005) and Mariani et al. (2005), and baseline allele frequency information was generated for each spawning location for each of the sampling years separately and for the combined information from replicate samples when preliminary analysis indicated no temporal allele frequency differentiation. Only temporal samples from locations 16 and 18 exhibited statistically significant variation and were treated separately throughout the analyses (Table 1). One microsatellite, locus Cpa112, exhibits genetic differentiation above neutral expectations (Larsson et al. 2007; Gaggiotti et al. 2009) and improves statistical power for population assignment (André et al. 2011). Genotype information was obtained for a total of 1900 individuals from 17 mixed fishery samples at high scoring success (average number of scored loci $=99 \%$ across loci and samples).

\section{Mixed-stock simulation analyses}

To compare the performance of different statistical approaches mixed-stock proportions were estimated using both a partly Bayesian approach implemented in the software BAYES (Pella \& Masuda 2001) and the conditional maximum likelihood based ap-

Table 2. Clupea harengus. Mixed-stock samples (sample ID refers to Fig. 1). Numbers of fish which were determined from otoliths to have been spawned in spring (expected to originate mainly in the western Baltic), autumn and winter (expected to originate mainly in the North Sea and English Channel, respectively) are given per sample, along with proportion of juveniles $(<2$ yr, expected to mainly originate in the North Sea) in the sample. -: no data available

\begin{tabular}{|c|c|c|c|c|c|c|c|c|c|}
\hline \multirow{2}{*}{ Location } & \multirow{2}{*}{$\begin{array}{l}\text { Sample } \\
\text { ID }\end{array}$} & \multirow{2}{*}{$\begin{array}{l}\text { Latitude/ } \\
\text { Longitude }\end{array}$} & \multirow{2}{*}{$\begin{array}{c}\text { Sample } \\
\text { date } \\
\text { (dd/mm/yr) }\end{array}$} & \multirow{2}{*}{$\begin{array}{c}\text { Proportion } \\
\text { juveniles }\end{array}$} & \multirow[t]{2}{*}{$\mathrm{n}$} & \multirow{2}{*}{ Spring } & \multicolumn{2}{|c|}{ - Spawning time } & \multirow[b]{2}{*}{$\begin{array}{l}\text { Undeter- } \\
\text { mined }\end{array}$} \\
\hline & & & & & & & Autumn & Winter & \\
\hline \multirow[t]{2}{*}{ Skagerrak West } & a1 & $57^{\circ} 53^{\prime} \mathrm{N} / 6^{\circ} 35^{\prime} \mathrm{E}$ & $29 / 06 / 02$ & 0.48 & 200 & 92 & 29 & 40 & 39 \\
\hline & $\mathrm{a} 2$ & $57^{\circ} 41^{\prime} \mathrm{N} / 6^{\circ} 55^{\prime} \mathrm{E}$ & 02/07/03 & 0.46 & 100 & 42 & 49 & 9 & 0 \\
\hline \multirow[t]{2}{*}{ Central Skagerrak } & b1 & $58^{\circ} 2^{\prime} \mathrm{N} / 8^{\circ} 22^{\prime} \mathrm{E}$ & 01/07/02 & 0.98 & 200 & 34 & 42 & 21 & 103 \\
\hline & $\mathrm{b} 2$ & $58^{\circ} 13^{\prime} \mathrm{N} / 8^{\circ} 57^{\prime} \mathrm{E}$ & 04/07/03 & 0.61 & 100 & 38 & 57 & 5 & 0 \\
\hline \multirow[t]{2}{*}{ Skagerrak North } & c1 & $58^{\circ} 37^{\prime} \mathrm{N} / 9^{\circ} 41^{\prime} \mathrm{E}$ & 03/07/02 & 0.13 & 100 & 26 & 3 & 0 & 71 \\
\hline & $\mathrm{c} 2$ & $58^{\circ} 34^{\prime} \mathrm{N} / 9^{\circ} 57^{\prime} \mathrm{E}$ & 06/07/03 & 0.23 & 100 & 73 & 22 & 3 & 2 \\
\hline \multirow[t]{2}{*}{ Skagerrak South } & d1 & $58^{\circ} 10^{\prime} \mathrm{N} / 10^{\circ} 7^{\prime} \mathrm{E}$ & 04/07/02 & 0.06 & 100 & 39 & 5 & 2 & 54 \\
\hline & $\mathrm{d} 2$ & $58^{\circ} 10^{\prime} \mathrm{N} / 10^{\circ} 5^{\prime} \mathrm{E}$ & 07/07/03 & 0.49 & 100 & 38 & 57 & 5 & 0 \\
\hline Grimstad & $\mathrm{e} 1$ & $58^{\circ} 20^{\prime} \mathrm{N} / 8^{\circ} 33^{\prime} \mathrm{E}$ & $17 / 12 / 02$ & 0 & 100 & 100 & 0 & 0 & 0 \\
\hline Høvåg & $\mathrm{e} 2$ & $58^{\circ} 8^{\prime} \mathrm{N} / 8^{\circ} 16^{\prime} \mathrm{E}$ & 03/11/03 & 0 & 100 & 91 & 0 & 0 & 9 \\
\hline Risør & $\mathrm{f} 1$ & $58^{\circ} 44^{\prime} \mathrm{N} / 9^{\circ} 15^{\prime} \mathrm{E}$ & $02 / 11 / 02$ & 0.62 & 100 & - & - & - & 100 \\
\hline Kragerø & $\mathrm{f} 2$ & $58^{\circ} 49^{\prime} \mathrm{N} / 9^{\circ} 27^{\prime} \mathrm{E}$ & $17 / 11 / 03$ & 0.38 & 100 & - & - & - & 100 \\
\hline \multirow[t]{2}{*}{ Langesund } & g1 & $59^{\circ} 0^{\prime} \mathrm{N} / 9^{\circ} 48^{\prime} \mathrm{E}$ & 09/12/02 & 0.02 & 100 & - & - & - & 100 \\
\hline & g2 & $59^{\circ} 0^{\prime} \mathrm{N} / 9^{\circ} 48^{\prime} \mathrm{E}$ & $17 / 11 / 03$ & 0 & 100 & - & - & - & 100 \\
\hline \multirow[t]{2}{*}{ Inner Skagerrak } & h1 & $58^{\circ} 45^{\prime} \mathrm{N} / 10^{\circ} 25^{\prime} \mathrm{E}$ & $04 / 11 / 02$ & 1 & 100 & - & - & - & 100 \\
\hline & h2 & $59^{\circ} 1^{\prime} \mathrm{N} / 10^{\circ} 31^{\prime} \mathrm{E}$ & $19 / 11 / 03$ & 0.04 & 100 & 96 & 1 & 0 & 3 \\
\hline Jeløya & i1 & $59^{\circ} 29^{\prime} \mathrm{N} / 10^{\circ} 37^{\prime} \mathrm{E}$ & $04 / 11 / 02$ & 0.04 & 100 & - & - & - & 100 \\
\hline
\end{tabular}


proach (Millar 1987) using the software ONCOR (S. Kalinowski, www.montana.edu/kalinowski/Software/ ONCOR.htm). Both approaches offer the possibility to estimate contributions to the mixture sample both from individual populations in the baseline, as well as from user defined groups of populations, here referred to as 'reporting groups'. The latter is useful in analyses where regional population contributions are of interest and where modest or low genetic differentiation yields low statistical power for determining individual contributions to the mixtures. Here, initial simulations indicated low statistical power for estimating contributions by individual population components. Thus all analyses of mixed-stock composition were conducted using 4 geographically based reporting groups: (1) the North Sea, (2) the Skagerrak, (3) Kattegat and inner Danish waters (KIDW), and (4) Rügen. The 4 groups exhibit statistically significant structuring at varying degrees, with the largest pairwise $F_{\mathrm{ST}} \mathrm{S}$ estimated between populations West and East of the transition zone, i.e. between the North Sea/Skagerrak and KIDW/Rügen populations $\left(F_{\mathrm{ST}} \mathrm{S}\right.$ between 1 and $\left.2 \%\right)$, and with smaller degrees of differentiation within each side of the transition zone i.e. between North Sea and Skagerrak $(\sim 0.3 \%)$ and between KIDW and Rügen ( 0.6\%) (Ruzzante et al. 2006).

Two series of simulation analyses were conducted to examine the accuracy and bias of composition estimates generated. The first series was aimed at examining how varying the skew in proportions of contributing populations affected the estimates, and the second examined the effect of mixture sample size. In both cases, the simulation approach implemented in ONCOR was used to produce mixtures of 100 genotypes by drawing alleles from reduced variance estimates of allele frequencies in spawners collected in 2002 to make mixture samples with known population contributions. We first constructed 4 series of simulated mixture samples, where the skew among contributing populations varied with twenty replicates per skew scenario (Table 3). Twenty replicates per scenario enabled us to assess accuracy at a $5 \%$ level, which was considered adequate given the estimated accuracy that could be attained with the applied set-up (see 'Results'). Secondly, 4 series of mixed-stock samples of 50,100, 150 and 200 multi-locus genotypes were constructed, with North Sea, Skagerrak, KIDW and Rügen contributing 40,5, 25 and $30 \%$, respectively, so as to simulate a relatively complex mixture scenario. Again, twenty replicates were produced for each sample size. The composition of simulated mixtures was estimated using baselines constructed with allele frequency information from herring collected in 2003. Constructing the baseline samples using the allele frequency distribution of the 2003 collection to estimate the composition of simulated mixture samples based on the allele frequencies of 2002 collections, ensures that allele frequency estimates in simulated mixture samples are independent of allele frequency estimates in baseline samples. Absence of this independence would be expected to lead to upward biasing of predictions about accuracy (e.g. Anderson et al. 2008). BAYES was run following standard procedures recommended in the user manual (Masuda 2002). Briefly, each mixture was analysed using 4 independent MCMC chains, run until convergence, as assessed by the Raftery \& Lewis (1996) diagnostic. Individual chains were started with $95 \%$ of the mixed sample initially contributed by one source population, and the rest were divided equally among the remaining populations. Across the 4 chains, all 4 reporting groups were represented as initially dominating. The Dirichlet prior distribution was set as a low information prior giving all population proportions equal weights. Convergence among chains was assessed with the Gelman \& Rubin (1992) diagnostic. Point estimates (means) and $95 \%$ probability intervals $(95 \% \mathrm{PI})$ for posterior MCMC samples of reporting groups were determined using only the second halves of chains combined (MCMC sample size 10000 per chain). ONCOR was run, using standard settings and $95 \%$ confidence intervals (abbreviated $95 \% \mathrm{CI}$ ) were assessed by 10000 bootstraps. Accuracy and bias of the estimates generated across simulations with ONCOR and BAYES were evaluated by the average absolute deviation between true and estimated proportions and by the mean square error (RMSE) and the relative bias (RBias).

For comparison, we also estimated MSA accuracy for the 4 reporting groups using the software BELS (Bromaghin 2008). In BELS, simulated mixtures of user specified size and population compositions are produced from baseline data by sampling with replacement single-locus genotypes from baseline individuals. This step is followed by MSA using conditional maximum likelihood to generate estimates of individual populations that are summed across populations within reporting groups. Using BELS we simulated mixture compositions with the same degrees of skew and sample sizes as simulations in Table 2, and replicated each scenario 1000 times. The approach thus enables analysis of a very large number of simulated samples. 


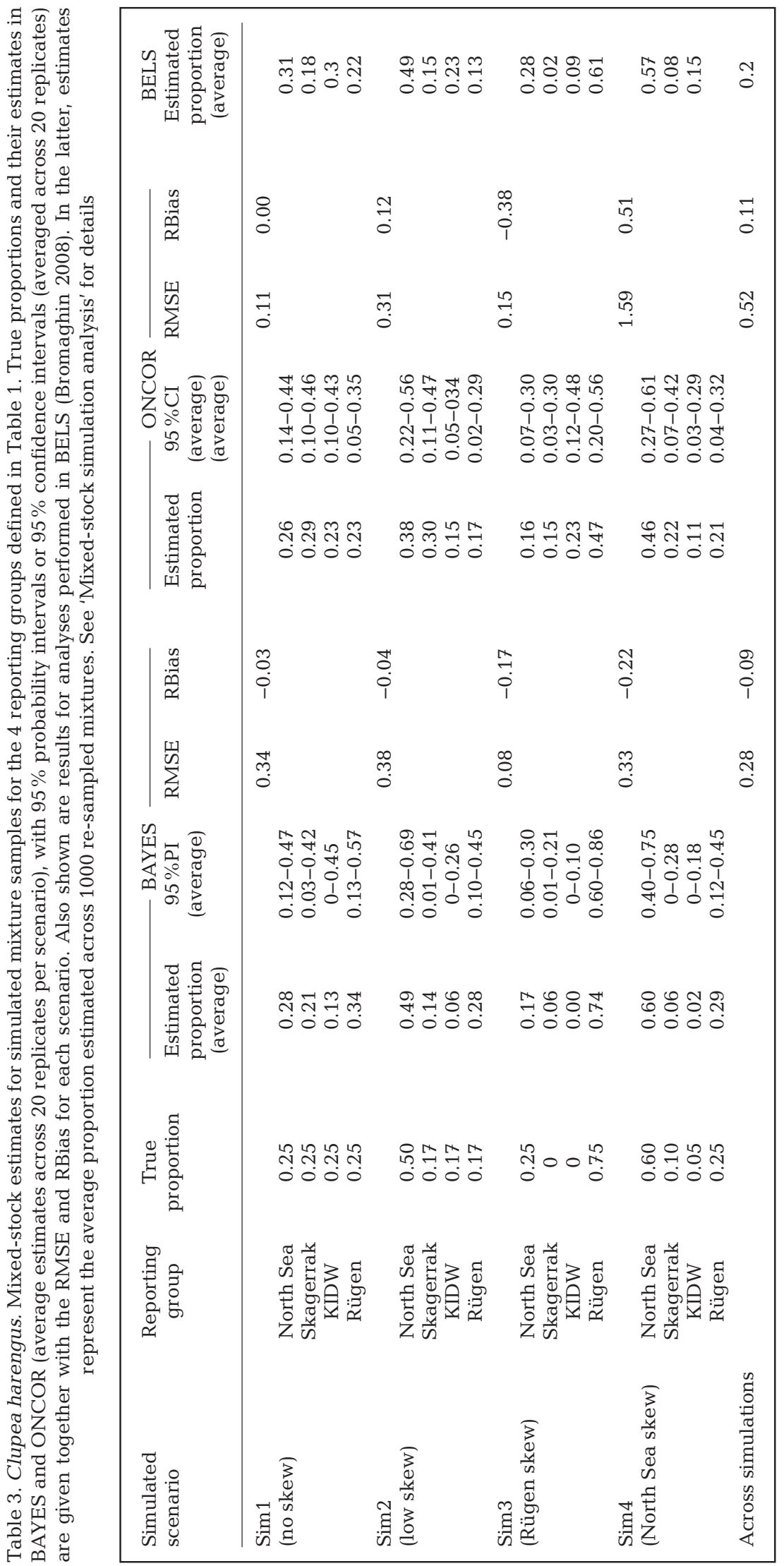

\section{Skagerrak mixed-stock fishery samples}

MSAs were carried out for each of 17 mixture samples, estimating contributions from the North Sea, Skagerrak, KIDW and Rügen using both BAYES and ONCOR. The baseline in these analyses comprised allele frequency information for all population samples, with temporal information combined within locations when applicable (i.e. including the full dataset in Table 1, with temporal samples from location 16, and March and combined April and May samples from location 18 entered as separate population samples). Analyses were performed using the same procedures as for simulated samples.

\section{RESULTS}

Composition estimates for simulated samples from BAYES and ONCOR generally returned estimates close to true proportions, although across individual simulations, compositions were over- or underestimated by up to $24 \%$ (BAYES) and $41 \%$ (ONCOR) (Table 3). BAYES estimates were overall more accurate and less biased than ONCOR estimates $(\mathrm{RMSE}=0.28$ and 0.52 for BAYES and ONCOR, respectively; RBias = -0.09 and 0.11 for BAYES and ONCOR, respectively). ONCOR tended to overestimate weakly contributing reporting groups and underestimate strongly contributing reporting groups, whereas BAYES displayed relatively low accuracy under the no-skew scenario (Table 3). Across simulations, average deviation between true and estimated proportion was $8 \%$ for BAYES and $11 \%$ for ONCOR. The simulations suggested that ONCOR and BAYES, respectively, tended to under- and overestimate propor- 
tions for Rügen, but that BAYES produced overall less biased results (Table 3). Confidence and probability intervals were generally broad for both BAYES and ONCOR (average $\sim 0.30$ for both approaches) and sometimes included zero for groups contributing up to $17 \%$ of the mixtures. $95 \%$ CIs for ONCOR sometimes did not include the true values or even the composition estimates (ONCOR authors note that this can be a problem). The $95 \%$ PIs and $95 \%$ CIs for non-contributing groups were narrow and always included zero in both BAYES and ONCOR. BELS analyses also indicated that contributions from the 4 reporting groups could be estimated with acceptable accuracy, as deviations between real and estimated proportions were generally low (average $=$ 0.05) (Table 3). For simulated mix-

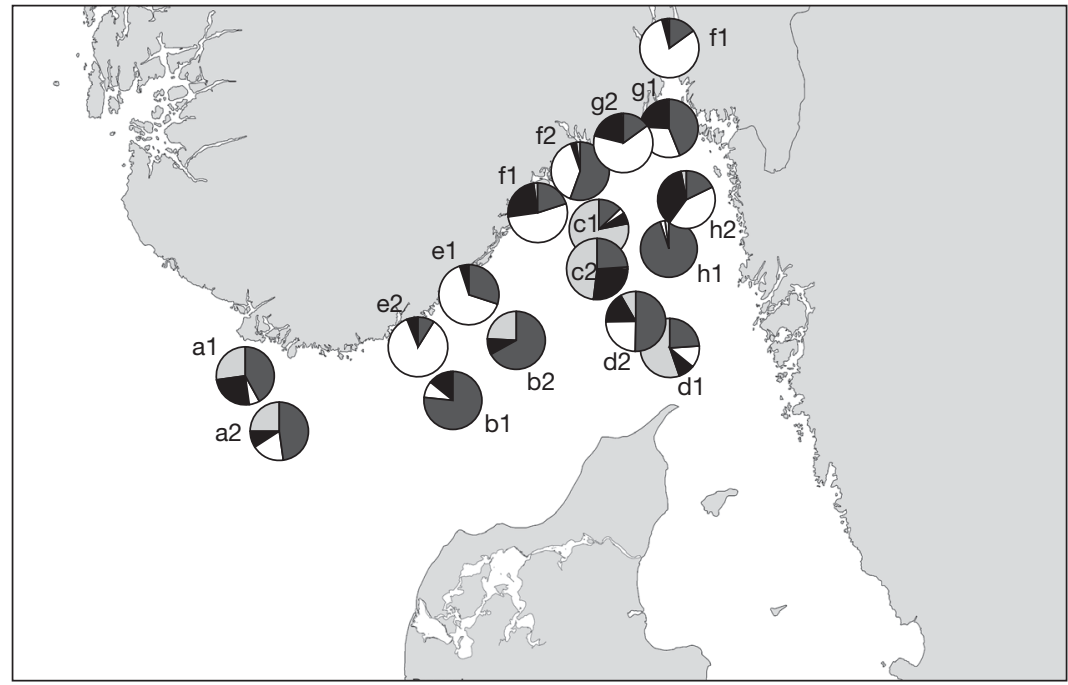

Fig. 2. Clupea harengus. BAYES estimates of proportional contributions from each of the reporting groups North Sea (dark grey in pie diagram), Skagerrak (white pie), KIDW (black pie) and Rügen (light grey pie) to 17 mixed-stock samples collected across 2 yr (sample numbers refer to Fig. 1 and Table 2, sample notations ' 1 ' and ' 2 ' indicate samples collected in 2002 and 2003, respectively; samples a-d were collected in summer and e-i in winter) tures of different sample sizes BAYES results indicated that $95 \%$ PIs decreased with increasing sample sizes, whereas average point estimates changed little and on average deviated from actual values by $0.12,0.07,0.05$ and 0.06 for sample sizes of 50, 100, 150 and 200, respectively (Table 4). Similar BELS simulations confirmed this result (data not shown).

\section{Skagerrak mixed-stocks}

The simulation analyses indicated that BAYES and ONCOR produced mixed-stock proportions at roughly similar levels of accuracy, with BAYES performing slightly better under skew. All 17 empirical samples exhibited evidence of skewed contributions

(see below), and, therefore, we only report BAYES estimates. When MSA results for the 17 fishery samples from locations a to i (Fig. 2) were compared, 3 main patterns emerged. First, herring of local Skagerrak origin were indicated to be present in very low numbers in most summer samples (a to d), and in 7 out of 8 samples lower 95\%PI included zero. Second, in stark contrast to this, local Skagerrak herring made up substantial proportions in samples collected in winter (e to i). Results indicated that Skagerrak herring often occurred together with North Sea herring (juveniles) or completely dominated the aggregations they were collected from, and only rarely schooled with fish originating in KIDW and Rügen. Third, whereas Rügen herring were found in all sum-

Table 4. Clupea harengus. Mixed-stock estimates for simulated mixtures, computed with BAYES for varying sample sizes (n) (reported as averages across 20 replicates per $n$ ) with average 95\% probability interval (95\%PI) and RMSE and RBias

\begin{tabular}{|c|c|c|c|c|c|c|c|c|c|}
\hline \multirow{2}{*}{$\begin{array}{l}\text { Reporting } \\
\text { group }\end{array}$} & \multirow{2}{*}{$\begin{array}{c}\text { True } \\
\text { proportion }\end{array}$} & \multicolumn{2}{|c|}{$\longrightarrow \mathrm{n}=50$} & \multicolumn{2}{|c|}{$\longrightarrow \mathrm{n}=100 \square$} & \multicolumn{2}{|c|}{$\longrightarrow \mathrm{n}=150$} & \multicolumn{2}{|c|}{$\mathrm{n}=200$} \\
\hline & & Proportion & $95 \%$ PI & Proportion & $95 \%$ PI & Proportion & $95 \%$ PI & Proportion & $95 \%$ PI \\
\hline North Sea & 0.40 & 0.32 & $0.12-0.52$ & 0.36 & $0.16-0.47$ & 0.36 & $0.25-0.50$ & 0.39 & $0.27-0.50$ \\
\hline Skagerrak & 0.05 & 0.23 & $0.04-0.50$ & 0.10 & $0.08-0.43$ & 0.11 & $0.05-0.30$ & 0.10 & $0.08-0.33$ \\
\hline KIDW & 0.25 & 0.18 & $0.04-0.45$ & 0.25 & $0.07-0.38$ & 0.23 & $0.06-0.28$ & 0.17 & $0.07-0.25$ \\
\hline Rügen & 0.30 & 0.27 & $0.03-0.42$ & 0.29 & $0.08-0.39$ & 0.30 & $0.18-0.41$ & 0.38 & $0.17-0.36$ \\
\hline RMSE & & 4.48 & & 1.69 & & 1.34 & & 1.11 & \\
\hline RBias & & -0.03 & & 0.08 & & -0.14 & & 0.08 & \\
\hline
\end{tabular}


mer samples and often made up the dominant part of western Baltic herring, they were estimated at very low proportions in all winter samples (all estimates below $3 \%$ ) and lower $95 \%$ PIs always included zero. North Sea herring were indicated in all collections, and were mostly with spring-spawning herring. Only one sample (h1) showed evidence of being completely dominated by North Sea herring (Fig. 2). Across the $2 \mathrm{yr}$, contributions from North Sea and Skagerrak population varied relatively little between samples from locations at a, b and c, whereas contributions from Rügen and KIDW varied considerably across all locations (Fig. 2). Apart from the fact that local Skagerrak herring dominated most samples, composition estimates for winter samples generally varied between years within locations, indicating no obvious trend for spatially differentiated habitat use among population components from the North Sea, KIDW, and Rügen within a given season.

Overall the MSA results corresponded with expectations from otolith estimated hatching season and age compositions, in that there were positive relationships between estimated contribution from North Sea populations in a sample and both proportions of juveniles (Spearman's rank correlation $\mathrm{r}_{\mathrm{S}}=0.81$ ) and proportions of herring estimated to have hatched in autumn or winter $\left(r_{S}=0.90\right)$ (compare Table 2 and Fig. 2). Nonetheless, comparisons also showed that some samples (f1) dominated by juveniles had low contributions from North Sea herring, whereas other samples ( $g 1, \mathrm{~d} 1, \mathrm{e} 1)$ with estimated contributions from the North Sea between 24 and $44 \%$ contained no or few $(<6 \%)$ juveniles. In winter samples, a positive relationship was found between proportions of adult and local Skagerrak herring $\left(\mathrm{r}_{\mathrm{S}}=0.70\right)$. Collectively, winter samples comprised only 19 juveniles out of 281 spring-spawned individuals (as assessed from otoliths), and a post hoc MSA of the origin of 74 spring-spawned juveniles encountered across summer samples estimated that only $1 \%$ (95\%PI 0-23\%) originated from the Skagerrak, whereas $21 \%$ (95\%PI $6-38 \%)$ were from the North Sea, $14 \%$ (95\%PI $0-36 \%$ ) from KIDW, and $60 \%$ (95\%PI $37-80 \%$ ) from Rügen.

\section{DISCUSSION}

The simulation analyses returned 2 main results. First, the applied statistical approaches in which population samples are grouped present useful tools for investigating habitat use and migratory behaviour for weakly differentiated populations, even across small spatial scales. Secondly, our simulations demonstrated that MSA can estimate contributions from specific populations, even in a weakly differentiated population scenario (in our case Rügen herring). Nonetheless, composition estimates deviated, on average, by almost $10 \%$ from true proportions indicating that the MSA results should be treated qualitatively, rather than quantitatively. Moreover, conclusive inference about presence/ absence of rare populations was not possible with the current design, as evidenced by the fact that, although noncontributing reporting groups came out with very low estimates, contributions of up to $17 \%$ to a mixture were associated with lower CIs including zero (Table 3). We found that the Bayesian method performed better than the conditional maximum likelihood method, which is in agreement with the expectation when highly polymorphic loci are used (e.g. Kalinowski 2004). For BAYES, the simulations indicated that for groups contributing more than $25 \%$ to a mixture, contribution estimates never deviated more than $10 \%$ from the true proportions. For ONCOR, estimates for groups contributing more than $25 \%$ regularly deviated by 20 to $40 \%$, and only in the (presumably biologically rare) no-skew scenario did ONCOR perform better than BAYES (Table 3). Simulation analyses hence indicated that BAYES estimates could be used to reliably detect major contributions from the 4 reporting groups and to indicate if reporting group contributions were rare or absent.

Simulation analyses are unlikely to completely predict MSA accuracy as sampling variance, temporal allele frequency variation, and violation of model assumptions may lead to error. A well known problem arises from using simulated mixture files constructed by re-sampling baseline genotypes, leading to underestimation of sampling variance, and to a corresponding overestimation of MSA accuracy (Anderson et al. 2008). Here, temporally replicated samples from baseline populations were available, allowing construction of baselines and simulated mixture files with independent genotypic information, thus minimising effects of sampling error on MSA predictions. The approach, however, does not incorporate the full information available, as allele frequency estimates are expected to improve with increased sample sizes. All our population samples were large overall (ca. 100 ind.), indicating that effects of sampling error on allele frequency estimates are unlikely to have been a major source of bias when estimating contributions of reporting groups to mixtures. Nonetheless, sampling error may have contributed to the fact that BAYES and ONCOR estimates were gener- 
ally more similar across empirical mixed-stocks $\left(\mathrm{r}_{\mathrm{S}}=\right.$ $0.97)$ than across simulated mixtures $\left(r_{S}=0.75\right)$, where baseline allele frequencies for the latter were estimated based on approx. half the number of individuals, compared to the former. It is thus expected that the simulations yield conservative estimates of MSA accuracy. In contrast to simulated mixtures, real mixed samples may contain individuals originating from unsampled, genetically differentiated populations. Estimation errors associated with occurrence of mixture individuals from unsampled baselines were initially addressed by Smouse et al. (1990) and Pella \& Masuda (2006) who suggested that the problem may be reduced when unsampled populations have some genetic similarity with populations in the baseline, as is expected under isolation-by-distance. Although our baselines were expected to comprise samples from all major population components in the area, the distribution of herring spawning sites is more or less continuous in the study area, and we are unlikely to have sampled all genetically distinct components contributing to mixed samples. However, the fact that $95 \%$ PIs differed little between simulated and empirical samples (average PI: Sim 1 to $4=0.309$; samples a1 to i1 $=0.286$ ) suggested that the overall resolution of simulated and empirical MSAs was similar and that contribution from unsampled populations was not likely to be a major error source. Due to logistic and resource constraints, fully comprehensive population sampling is generally unlikely to be attainable in most marine MSA applications. Our results thus demonstrate that even though failure to sample all baseline populations may affect MSA accuracy, sampling error need not pose a problem for regional estimates.

Population allele frequencies may vary over time, e.g. through random genetic drift among cohorts (Jorde \& Ryman 1995) or as an artifact of inconsistent sampling of sub-structured populations, and this may pose another source of error in MSA applications. Such effects are, however, expected to contribute little to allele frequency variation in marine organisms with extensive overlap between generations and the presumed very large effective population sizes. Our analysis comprised populations exhibiting lower differentiation than MSA studies in most other marine species (Wirgin et al. 1997, Ruzzante et al. 2000, 2006, Beacham et al. 2008, Wennevik et al. 2008) and approximately an order of magnitude lower than MSA studies in salmonids (Ruzzante et al. 2004, Beacham et al. 2005, Koljonen et al. 2005, Smith et al. 2005, Gauthier-Ouellet et al. 2009). Using BAYES with data for 8 microsatellite loci typed in 26 Atlantic salmon populations, Koljonen et al. (2005) reported that deviation between true and estimated single population contributions averaged $3 \%$ in a composite self-assignment test (i.e. simulated mix-samples consisted of multi-locus genotypes re-sampled from the baseline). Although their study estimated population- (and not region-) specific mixed-stock contributions, the comparable levels of accuracy observed in their study and ours emphasize that even at low population differentiation, as e.g. $F_{\mathrm{ST}}<0.02$, MSA accuracy may be within acceptable limits for biological inference.

Kalinowski (2004) used a fully simulated dataset to examine performance of maximum-likelihood based MSA under various levels of marker polymorphism and baseline sample sizes. He found that maximal MSA accuracy was obtained by analysing ca. 100 ind. per baseline population using markers with a high number of independent alleles per locus (in the range of ca. 20 to 250) and that accuracy was independent of levels of population differentiation for $F_{\mathrm{ST}} \mathrm{S}$ ranging between 0.01 and 0.16 . These conditions were predicted to apply to the BAYES approach also (Kalinowski 2004). Very high polymorphism and allelic richness are typical for microsatellite marker studies in marine fishes and also in our study (heterozygosity and numbers of alleles per locus averaged across samples and loci were 0.820 and 26, respectively). Our approach and sampling scheme should thus yield close to maximal statistical power with the given markers, and the results can be used to predict power in other marine MSA applications exhibiting similar levels of differentiation and with similar combinations of markers and sample sizes.

The accuracy of MSA estimates is potentially affected by the composition in the mixed-stock, as well as coverage of the baseline. Mixtures exhibiting low contribution skew (i.e. all components present contribute similar proportions) are expected to return better estimates than mixtures with high skew in relative population contributions (Koljonen et al. 2005). Contributions from lesser components tend to be overestimated with most algorithms, with corresponding underestimation of larger proportions (e.g. Reynolds \& Templin 2004). With the Bayesian method we did not observe that simulations with lower skew among contributing components exhibited higher accuracy, and rare components were both over- and underestimated (Table 3). In contrast, ONCOR produced overall more biased estimates, and in several cases overestimated contributions from low- or non-contributing reporting groups by more than $10 \%$. 
Varying sample sizes of simulated mixtures mainly affected $95 \%$ PI and only to a small extent composition point estimates (Table 4), showing that sample sizes of 100 were adequate for inference about composition of the Skagerrak fishery samples. Point estimates for the Skagerrak reporting group contributing $5 \%$ approached zero in all cases, showing that power for detecting presence/absence of rare components did not increase significantly even with a fourfold increase in sample size.

Re-analysis of stock composition for the 17 feeding samples that were pooled and analysed for a different set of reporting groups in Ruzzante et al. (2006) generated novel information about herring migratory behaviour. The tendency for samples to show some stability in composition across the 2 sampling years suggests stable spatial structure and habitat use of individual population components (Fig. 2). This was illustrated by western locations a and b comprising high proportions of North Sea fish in both years, whereas a relatively strong dominance of Rügen fish was observed for eastern locations $\mathrm{c}$ and $\mathrm{d}$ in 2002. At d in 2003, juvenile North Sea herring dominated together with local Skagerrak herring. Variance in composition among schools sampled in the same general area and the same time of the year is expected to be large, and our sampling scheme is unlikely to be adequate for fully resolving population differences in habitat use in the study area. Our analysis nonetheless demonstrated that local Skagerrak fish were present and often dominated aggregations sampled in winter. Winter samples were generally collected closer to the coast than summer samples, and we are thus not able to discount that the large seasonal differences in compositions could be an effect of coastal vs. offshore distributions of populations. The one deviation from dominance of local Skagerrak herring in winter samples was in fact the h1 sample of juveniles exclusively of North Sea origin, which incidentally was also the winter sample collected furthest offshore. However, local origin Skagerrak herring were also indicated to dominate the offshore winter sample h2, and our data clearly show that Skagerrak fish were present also in samples collected offshore in summer, and thus that spatial segregation of local herring is not just a question of inshore or offshore habitat.

There was generally good correspondence between estimated ages, otolith-assessed spawning times, and sample compositions, supporting the assumption that North Sea herring in the area are mainly represented by juveniles hatched in autumn or winter, whereas western Baltic herring in the area are mainly spring-spawning adults (Rosenberg \& Palmén 1982). Previous attempts to infer migratory behaviour from catch statistics separated according to age groups and morphmetrics have failed to reliably distinguish among populations from the western Baltic (e.g. from the Rügen vs. other western Baltic populations) and in some cases even among herring from the Norwegian Sea and the Baltic Seas) (e.g. Payne et al. 2009). The efficiency of morphometric methods to reliably distinguish among populations is likely to vary among years in response to changes in environment, some of which are known to affect morphological traits (e.g. Bierman et al. 2010). Similarly, spawning time, as assessed from otoliths, is not a reliable indicator of population origin, as spawning time can vary within populations (e.g. Bekkevold et al. 2007).

Here, using a suite of 9 microsatellite loci we were able to gain novel insights at lower structural levels. We found no evidence that Skagerrak juveniles feed or overwinter in any of the sampled areas, which, incidentally, are important feeding and overwintering habitat for juvenile North Sea herring. Neither the location of juvenile Skagerrak herring feeding grounds nor the spatial segregation between juvenile and adult Skagerrak herring have, to our knowledge, been described. However, spatial segregation among juveniles from individual spring-spawning populations may facilitate subsequent natal homing (Corten 2001, Gaggiotti et al. 2009) and thus contribute to the relatively large reproductive isolation between populations from the Skagerrak and KIDW (Bekkevold et al. 2005). The relatively high proportion of springspawned juveniles of genetic North Sea origin is interesting. These individuals could potentially represent juveniles from the Norwegian Sea springspawning population that cannot be genetically distinguished from North Sea autumn-spawning herring with the applied set of markers (Mariani et al. 2005). The observation that some samples with no or few juveniles and no or few autumn- or winterspawning individuals ( $\mathrm{d} 1$, e1 and $\mathrm{g} 1$ ) contained substantial proportions of North Sea herring could also suggest migration of Norwegian Sea springspawning herring. However, feeding migration of Norwegian herring to the Skagerrak has not been described and resolving their origin requires more targeted analyses involving markers that allow separation of North Sea and Norwegian populations.

We found that contrary to previous understanding (e.g. Rosenberg \& Palmén 1982) herring spawning in the KIDW were found to be present in considerable numbers throughout the Skagerrak. Pooling across 
spatial samples and years, their contributions were estimated at $14 \%$ in summer and $13 \%$ in winter, translating into respective contributions of 24 and $20 \%$ of all (spring-spawning) western Baltic herring in the Skagerrak. Current fisheries management advise for TAC for the Skagerrak mixed fishery is set at a level compatible with a precautionary exploitation of western Baltic Sea herring and is based on the assumption that Rügen herring constitute the majority of spring-spawning herring in the area (ICES 2010). Although our results support the notion that Rügen herring constitute an important component in the Skagerrak, they also show that the proportion of spring-spawning herring in the Skagerrak represents an inaccurate proxy for the size of the Rügen component.

In summer, Rügen fish contributed substantially to most collections. However, in winter they were absent from all collections, in agreement with inference from mark-recapture studies that Rügen herring leave their western Baltic spawning grounds in the 2nd quarter of the year to feed in the Skagerrak and eastern North Sea in summer, followed by return to spawning locations in the following 1st quarter (Biester 1979, Nielsen et al. 2001, van Deurs \& Ramkaer 2007, Payne et al. 2009). The fact that the Rügen herring were rare or absent from all our November samples collected across 2 years suggests that their return migration may have started before, or during the 4 th quarter. This pattern also supports the assertion from morphometric and otolith studies that Rügen herring overwinter south of the Skagerrak, in the western Baltic (Rosenberg \& Palmén 1982, Nielsen et al. 2001). In contrast, several winter samples contained Kattegat herring and herring from the inner Danish waters in considerable proportions (compare Fig. 2 samples a to d with e to i). We interpret these results as indicating that habitat use and migratory behaviour differ profoundly between the Rügen and KIDW herring. As mentioned, summer samples were collected offshore and most winter samples were collected inshore (Fig. 1), and we therefore cannot directly describe the seasonal variation in mixed-stock composition. However, we identified large differences in habitat use and migratory behaviour among (spring) spawning components, demonstrating that even for organisms exhibiting weak population differentiation, the MSA approach is a powerful tool that can be tailored to answering specific biological and management questions. In the case of the Rügen herring, the current assessment procedure assumes that Rügen is the strongest contributor to the spring spawning stock occurring throughout the area spanning from the eastern North Sea to the western Baltic, and uses a recruitment estimate based solely on this population (ICES 2010). However, our findings suggest that including recruitment estimates on a more local population scale would reduce noise around this estimate. Our results thus also strongly support the notion (e.g. Schindler et al. 2010) that marine fish management needs to incorporate knowledge about individual population dynamics to allow sustainable exploitation.

Acknowledgements. This work is part of the research project HERGEN (www.hull.ac.uk/hergen) funded by the European Union within the 5th framework programme. H. Mosegaard, B. Hutchinson, J. Simmonds, L. Larsson, L. Laikre, T. Dahlgren and the late R. Stet contributed valuable comments during discussions and we thank them all.

\section{LITERATURE CITED}

Anderson EC, Waples RS, Kalinowski ST (2008) An improved method for predicting the accuracy of genetic stock identification. Can J Fish Aquat Sci 65:1475-1486

André C, Larsson LC, Laikre L, Bekkevold D and others (2011) Detecting population structure in a high geneflow species, Atlantic herring (Clupea harengus): direct, simultaneous evaluation of neutral versus putatively selected loci. Heredity 106:270-280

Aro E (1989) A review of fish migration patterns in the Baltic. Rapp P-V Réun Cons Int Explor Mer 190:72-96

$>$ Beacham TD, Candy JR, McIntosh B, MacConnachie C and others (2005) Estimation of stock composition and individual identification of sockeye salmon on a Pacific Rim basis using microsatellite and major histocompatibility complex variation. Trans Am Fish Soc 134:1124-1146

Beacham TD, Schweigert JF, MacConnachie C, Le KD, Flostrand L (2008) Use of microsatellites to determine population structure and migration of Pacific herring in British Columbia and adjacent regions. Trans Am Fish Soc 137:1795-1811

Bekkevold D, André C, Dahlgreen TG, Clausen LAW and others (2005) Environmental correlates of population differentiation in Atlantic herring. Evolution 59:2656-2668

- Bekkevold D, Clausen LAW, Mariani S, Andre C, Christensen TB, Mosegaard H (2007) Divergent origins of sympatric herring population components determined using genetic mixture analysis. Mar Ecol Prog Ser 337: 187-196

> Bierman SM, Dickey-Collas M, van Damme CJG, van Overzee HMJ, Pennock-Vos MG, Tribuhl SV, Clausen LAW (2010) Between-year variability in the mixing of North Sea herring spawning components leads to pronounced variation in the composition of the catch. ICES J Mar Sci 67:885-896

Biester E (1986) The distribution of the Rügen spring herring. J Cons Int Explor Mer 42(3):281-294

Bromaghin JF (2008) BELS: backward elimination locus selection for studies of mixture composition or individual assignment. Mol Ecol Res 8:568-571

Clausen LAW, Bekkevold D, Hatfield EMC, Mosegaard H (2007) Application and validation of otolith microstructure as stock identifier in mixed Atlantic herring (Clupea 
harengus) stocks in the North Sea and western Baltic. ICES J Mar Sci 64:377-385

Corten A (1986) On the causes of the recruitment failure of herring in the central and northern North Sea in the years 1972-1978. J Cons Perm Int Explor Mer 42:281-294

Corten A (2001) The role of 'conservatism' in herring migrations. Rev Fish Biol Fish 11:339-361

Gaggiotti OE, Bekkevold D, Jorgensen HBH, Foll M, Carvalho GR, Andre C, Ruzzante DE (2009) Disentangling the effects of evolutionary, demographic, and environmental factors influencing genetic structure of natural populations: Atlantic herring as a case study. Evolution 63:2939-2951

Gauthier-Ouellet M, Dionne M, Caron F, King TL, Bernatchez L (2009) Spatiotemporal dynamics of the Atlantic salmon (Salmo salar) Greenland fishery inferred from mixed-stock analysis. Can J Fish Aquat Sci 66:2040-2051

Gelman A, Rubin DB (1992) Inference from iterative simulation using multiple sequences. Stat Sci 7:457-511

ICES (International Council for Exploration of the Sea) (2003) Report of Herring Assessment Working Group for the area south of $62^{\circ} \mathrm{N}$. ICES CM 2003/ACFM:17

ICES (International Council for Exploration of the Sea) (2010) Report of the Herring Assessment Working Group for the area south of $62^{\circ} \mathrm{N}$. ICES CM 2010/ACOM:06

> Iles TD, Sinclair M (1982) Atlantic herring: stock discreteness and abundance. Science 215:627-633

> Johannessen A, Moksness E (1991) Occurrence of herring larvae in the Skagerrak area from December 1987 to April 1988. Fish Res 11:155-170

$>$ Jorde PE, Ryman N (1995) Temporal allele frequency change and estimation of effective size in populations with overlapping generations. Genetics 139:1077-1090

Jørgensen HBH, Hansen MM, Bekkevold D, Ruzzante DE, Loeschcke V (2005a) Marine landscapes and population structure of herring (Clupea harengus L) in the Baltic Sea. Mol Ecol 14:3219-3234

Jørgensen HBH, Hansen MM, Loeschcke V (2005b) Springspawning herring (Clupea harengus L) in the southwestern Baltic Sea: Do they form genetically distinct spawning waves? ICES J Mar Sci 62:1065-1075

Kalinowski ST (2004) Genetic polymorphism and mixed-stock fisheries analysis. Can J Fish Aquat Sci 61:1075-1082

Kell LT, Dickey-Collas M, Hintzen NT, Nash RDM, Pilling GM, Roel BA (2009) Lumpers or splitters? Evaluating recovery and management plans for metapopulations of herring. ICES J Mar Sci 66:1776-1783

Kerr LA, Cadrin SX, Secor DH (2010) Simulation modelling as a tool for examining the consequences of spatial structure and connectivity on local and regional population dynamics. ICES J Mar Sci 67:1631-1639

Koljonen ML, Pella JJ, Masuda M (2005) Classical individual assignments vs mixture modelling to estimate stock proportions in Atlantic salmon catches from DNA microsatellite data. Can J Fish Aquat Sci 62:2143-2158

Larsson LC, Laikre L, Palm S, André C, Carvalho GR, Ryman N (2007) Concordance of allozyme and microsatellite differentiation in a marine fish, but evidence of selection at a microsatellite locus. Mol Ecol 16:1135-1147

> Manel S, Gaggiotti OE, Waples RS (2005) Assignment methods: matching biological questions techniques with appropriate. Trends Ecol Evol 20:136-142

Mariani S, Hutchinson WF, Hatfield EMC, Ruzzante DE and others (2005) North Sea herring population structure as revealed by microsatellite analysis. Mar Ecol Prog Ser $303: 245-257$
Masuda M (2002) User's Manual for Bayes: Bayesian Stock Mixture Analysis Program. National Marine Fisheries Service, Alaska Fisheries Science Center, Auke Bay Laboratory, Juneau, AK

Millar RB (1987) Maximum likelihood estimation of mixed stock fishery composition. Can J Fish Aquat Sci 44: 583-590

Miller JA, Bellinger MR, Golden JT, Fujishin L, Banks MA (2010) Integration of natural and artificial markers in a mixed stock analysis of Chinook salmon (Oncorhynchus tshawytscha). Fish Res 102:152-159

Nielsen JR, Lundgren B, Jensen TF, Staehr KJ (2001) Distribution, density and abundance of the western Baltic herring (Clupea harengus) in the Sound (ICES Subdivision $23)$ in relation to hydrographical features. Fish Res 50: 235-258

Payne MR, Clausen LW, Mosegaard H (2009) Finding the signal in the noise: objective data-selection criteria improve the assessment of western Baltic spring-spawning herring. ICES J Mar Sci 66:1673-1680

Pella J, Masuda M (2001) Bayesian methods for analysis of stock mixtures from genetic characters. Fish Bull 99: 151-167

Pella J, Masuda M (2006) The Gibbs and split-merge sampler for population mixture analysis from data with incomplete baselines. Can J Fish Aquat Sci 63:576-596

Raftery AE, Lewis SM (1996) Implementing MCMC. In: Gilks WR, Richardson S, Spiegelhalter DJ (eds) Markov chain Monte Carlo in practice, Chapman \& Hall, London, p 115-130

> Reynolds JH, Templin WD (2004) Detecting specific populations in mixtures. Environ Biol Fishes 69:233-243

Rosenberg R, Palmén LE (1982) Composition of herring stocks in the Skagerrak-Kattegat and the relations of these stocks with those of the North Sea and adjacent waters. Fish Res 1:83-104

Ruzzante DE, Taggart CT, Lang S, Cook D (2000) Mixedstock analysis of Atlantic cod near the Gulf of St Lawrence based on microsatellite DNA. Ecol Appl 10:1090-1109

Ruzzante DE, Hansen MM, Meldrup D, Ebert KM (2004) Stocking impact and migration pattern in an anadromous brown trout (Salmo trutta) complex: where have all the stocked spawning sea trout gone? Mol Ecol 13: 1433-1445

Ruzzante DE, Mariani S, Bekkevold D, André C and others (2006) Biocomplexity in a highly migratory pelagic marine fish, Atlantic herring. Proc R Soc Lond B Biol Sci 273:1459-1464

> Schindler DE, Hilborn R, Chasco B, Boatright CP, Quinn TP, Rogers LA, Webster MS (2010) Population diversity and the portfolio effect in an exploited species. Nature 465: 609-612

Smith CT, Templin WD, Seeb JE, Seeb UW (2005) Single nucleotide polymorphisms provide rapid and accurate estimates of the proportions of US and Canadian Chinook salmon caught in Yukon River fisheries. N Am J Fish Manag 25:944-953

> Smouse PE, Waples RS, Tworek JA (1990) A genetic mixture analysis for use with incomplete source population data. Can J Fish Aquat Sci 47:620-634

> van Deurs M, Ramkaer K (2007) Application of a tag parasite, Anisakis sp., indicates a common feeding migration for some genetically distinct neighbouring populations of herring, Clupea harengus. Acta Ichthyol Piscat 37:73-79

- Waples RS, Gaggiotti O (2006) What is a population? An empirical evaluation of some genetic methods for identi- 
fying the number of gene pools and their degree of connectivity. Mol Ecol 15:1419-1439

Waples RS, Naish KA (2009) Genetic and evolutionary considerations in fishery management: research needs for the future. Fish Fish 31:427-451

Ward RD, Woodwark M, Skibinski DOF (1994) A comparison of genetic diversity levels in marine, fresh-water, and anadromous fishes. J Fish Biol 44:213-232

> Wennevik V, Jorstad KE, Dahle G, Fevolden SE (2008)

Editorial responsibility: Per Palsböll, Stockholm, Sweden
Mixed stock analysis and the power of different classes of molecular markers in discriminating coastal and oceanic Atlantic cod (Gadus morhua L.) on the Lofoten spawning grounds, northern Norway. Hydrobiologia 606:7-25

Wirgin IL, Waldman JR, Maceda L, Sabile J, Vecchio VJ (1997) Mixed-stock analysis of Atlantic coast striped bass (Morone saxatilis) using nuclear DNA and mitochondrial markers. Can J Fish Aquat Sci 54:2814-2826

Submitted: January 19, 2011; Accepted: August 17, 2011 Proofs received from author(s): November 16, 2011 